\title{
Reliability-based service life assessment of concrete structures in nuclear power plants: optimum inspection and repair
}

\author{
Ellingwood, B.R. ', Mori, Y. ${ }^{2}$ \\ 1) Johns Hopkins University, Baltimore, U.S.A. \\ 2) Nagoya University, Nagoya, Japan
}

\begin{abstract}
Research is being conducted to address aging management of safety-related reinforced concrete structures in nuclear power plants (NPPs). Documentation is being prepared to identify potential structural safety issues and to recommend criteria for use in evaluating reinforced concrete structures for continued service. Time-dependent reliability analysis provides the framework and quantitative tools for the condition assessment. The role of in-service inspection and repair in ensuring continued reliability in service is examined.
\end{abstract}

\section{INTRODUCTION}

During the next 15 years, the operating licenses for a number of nuclear power plants (NPPs) in the United States will expire. Utilities may decide to seek renewals of these licenses rather than to face the substantial costs associated with replacing lost generating capacity, plant shutdown and decommissioning. Evaluation of a NPP facility with regard to its suitability for continued service encompasses structural, mechanical and electrical components (Vora, 1991; Shah and Hookham, 1994). While structural components generally play a passive role in mitigating accidents from internal events, they play a significant role in maintaining plant safety when accidents are initiated by extreme environmental events. In contrast to many mechanical and electrical components, structural replacement is not practical and their failure may lead to malfunction of other appurtenant systems. The evaluation of structures for continued service must provide quantitative evidence that their condition has not deteriorated due to aging or other factors to the point where their capacity to mitigate future extreme operating or environmental events within the proposed future service period is impaired. To achieve the desired performance goals, structures may have to be inspected and maintained periodically to ensure the necessary level of reliability during a projected service life extension.

The Structural Aging Program (SAG) is being conducted to: (1) identify and evaluate potential structural degradation processes in safety-related concrete structures; (2) define issues to be addressed during reviews for continued service and technical bases and criteria for resolution of these issues; (3) identify and evaluate relevant in-service inspection, assessment and remedial measures; and (4) develop reliability-based methodologies and engineering decision tools to perform such assessments and evaluations (Naus, et al, 1993). Significant progress has been made in identifying material property databases, critical structural components in NPPs (Hookham, 1991), nondestructive strength evaluation of concrete (Snyder, et al, 1992), and repair strategies (Krauss, 1994).

Reliability-based methodologies integrate information on design requirements, material and structural degradation and damage accumulation, environmental factors and non-destructive 
evaluation (NDE) technology into a decision tool that provides a quantitative measure of structural reliability under projected future service conditions (Ellingwood and Mori, 1993; Mori and Ellingwood, 1993, 1994a, 1994b). Optimum in-service inspection/maintenance strategies can be determined within this structural reliability framework to meet performance goals stated in probabilistic terms. This research has highlighted the need for quantitative modeling of strength degradation and the impact of NDE on in-service condition assessment.

\section{MECHANISMS OF DETERIORATION IN CONCRETE STRUCTURES}

\subsection{Service history of concrete structures}

The performance of concrete containments and other safety-related structures in NPPs generally has been very good. Some instances of deterioration have been reported, however (Naus, et al 1993; Shah and Hookham, 1994). Where deterioration has been observed, it generally has occurred early in the life of the plant and has been corrected. Mechanisms of potential aging and deterioration in reinforced concrete structures include corrosion of reinforcement, detensioning of prestressing tendons, and deterioration of concrete due to attack by sulfates (particularly magnesium sulfates) or other chemicals or frost, expansive aggregate (primarily alkali-silica) reactions, and leaching or salt recrystallization. One concern in structural aging studies is the inaccessibility of certain reinforced concrete components that have been judged to be important for maintaining plant safety (Hookham, 1991), particularly components below grade that are exposed to soil and groundwater. Another is that most concrete containments and other structures in NPPs have seen less than 25 to 30 years of service. The question arises as to whether degradation mechanisms such as those identified above could cause damage to reinforced concrete structures after years of apparently satisfactory service.

\subsection{Mathematical models of degradation}

Time-dependent reliability analysis and service life predictions for reinforced concrete structures require time-dependent stochastic models of structural strength. In concept, these stength models can be derived from: (1) mathematical models describing the effects of service and environmental factors on aging steel and concrete materials; (2) accelerated life testing; or (3) a combination of the two. At the current state of the art, aging effects usually are known qualitatively; however, quantitative models that describe material degradation processes often are empirical in nature (Clifton and Knab, 1989).

The depth of deteriorated concrete or steel often can be modeled to an acceptable approximation by

$$
\mathrm{X}(\mathrm{t})=\mathrm{C}\left(\mathrm{t}-\mathrm{t}_{\mathrm{i}}\right)^{\alpha}
$$

in which $\mathrm{t}=$ time, $\mathrm{t}_{\mathrm{i}}=$ induction or initiation time required to activate the deterioration process, $\mathrm{C}=$ rate parameter, and $\alpha=$ time-order parameter. The parameters $\mathrm{C}$ and $\alpha$ must be determined from experimental data. One must be cautious in using the results of accelerated aging tests to determine $\mathrm{C}$ and $\alpha$, as the mechanisms may not scale properly from the laboratory to the prototype. For processes that are essentially diffusion-controlled (corrosion of steel reinforcement), $\alpha=1 / 2$; for other degradation mechanisms (sulfate attack), $\alpha$ may be greater than 1 . In time-dependent reliability analysis, $C$ and $t_{i}$ are modeled as random variables.

Structural resistance, $R(t)$, can be related to $X(t)$ for a given behavioral limit state of interest, 
such as flexure, shear or compression. It can be assumed conservatively that the degraded material is totally ineffective in resisting force. The relation between $R(t)$ and $X(t)$ may be nonlinear, depending on the nature of the attack and the mechanics of the limit state.

\section{RELIABILITY-BASED METHODS FOR CONDITION ASSESSMENT}

\subsection{Time-dependent reliability analysis}

Structural loads, engineering material properties and strength degradation mechanisms are random in nature. Time-dependent reliability analysis methods provide a framework for the analysis of uncertainty in loads and residual strength of aging reinforced concrete structures. Sources of uncertainty that complicate the evaluation of aging effects on the residual strength arise from: (1) differences in design codes and standards for components of different ages; (2) lack of in-service measurements and records; (3) variations in service loads; (4) limitations in available models for quantifying time-dependent material changes and their contribution to structural capacity; (5) limitations in nondestructive evalution (NDE) technologies applied in difficult field circumstances; and (6) shortcomings in existing methods for rehabilitation and repair.

The failure probability of a structural component can be evaluated as a function of (an interval of) time if stochastic processes defining the residual strength and the probabilistic characteristics of the loads at any time are known. The strength, $R(t)$, of the structure and applied loads, $S(t)$, both are random functions of time. At any time, $t$, the margin of safety, $M(t)$, is,

$$
M(t)=R(t)-S(t)
$$

Making the customary assumption that $\mathrm{R}$ and $\mathrm{S}$ are statistically independent, the (instantaneous) probability of failure is,

$$
P_{f}(t)=P[M(t)<0]=\int_{o}^{\infty} F_{R}(x) f_{S}(x) d x
$$

in which $F_{R}(x)$ and $f_{S}(x)$ are cumulative distribution function (CDF) of $R$ and probability density function (PDF) of $S$. Eqn 3 provides an instantaneous quantitative measure of structural reliability, provided that $P_{f}(t)$ can be estimated and/or validated (Ellingwood, 1992).

For service life prediction and reliability assessment, one is more interested in the probability of satisfactory performance over some period of time, say $(0, t)$, than in the snapshot of the reliability at a particular time provided by Eqn 3. Indeed, it is difficult to use reliability-based engineering decision analysis without having some time period (expected service life or in-service inspection interval) in mind. The probability that a structure survives during interval $(0, t)$ is defined by a reliability function, $L(0, t)$. If, for example, $n$ discrete loads $S_{1}, S_{2}, \ldots, S_{n}$ occur at times $\left(t_{1}, t_{2}, \ldots . t_{n}\right)$ during $(0, \mathrm{t}), \mathrm{L}(0, \mathrm{t})$ becomes,

$$
\mathrm{L}(0, \mathrm{t})=\mathrm{P}\left[\mathrm{R}\left(\mathrm{t}_{1}\right)>\mathrm{S}_{1}, \ldots \mathrm{R}\left(\mathrm{t}_{\mathrm{n}}\right)>\mathrm{S}_{\mathrm{n}}\right]
$$

If the load process is continuous rather than discrete, an analogous expression derived from an upcrossing analysis (Veneziano, et al, 1977) can be used to obtain an approximation to Eqn 4.

The reliability function can be related to the hazard function, $h(t)$, defined as the conditional probability of failure within time interval $(t, t+d t)$, given that the component has survived during $(0, t)$. One has (Ellingwood and Mori, 1993), 


$$
L(0, t)=\exp \left[-\int_{0}^{t} h(x) d x\right]
$$

The hazard function is especially useful in analyzing structural failures due to aging or deterioration. For example, the probability that the time at structural failure, $T_{f}$, occurs prior to future maintenance scheduled at $t+\Delta t$, given that the structure has survived to $t$, can be evaluated as,

$$
P\left[T_{f} \leq t+\Delta t \mid T_{f}>t\right]=1-\exp \left[-\int_{t}^{t \cdot \Delta t} h(x) d x\right]
$$

In turn, the structural reliability for a succession of inspection periods is,

$$
L(0, t)=\underset{i}{\Pi} L\left(t_{i-1}, t_{i}\right) \exp \left[-\int_{t_{i}}^{t} h(x) d x\right]
$$

in which $t_{i-1}=0$ when $i=1$. Note that failures in successive intervals $\left(t_{i-1}, t_{i}\right)$ generally are not statistically independent.

The hazard function for purely chance failures is constant in time. When structural aging occurs and strength deteriorates, $h(t)$ characteristically increases with time. Moreover, as will be shown subsequently, in-service inspection and maintenance (ISI/M) impacts the reliability analysis through the hazard function, causing it to change discontinuously at the time that ISI/M is performed. Indeed, undegrading and degrading structural components can be distinguished in a time-dependent reliability analysis by their hazard functions. Much of the challenge in analyzing reliability of deteriorating reinforced concrete structural components lies in relating the hazard functions to specific degradation mechanisms such as corrosion of reinforcement and chemical attack or expansive aggregate reactions in concrete.

It will be assumed in the sequel that significant structural loads can be modeled as a sequence of load pulses, the occurrence of which is described by a Poisson process with mean rate of occurrence, $\lambda$, random intensity, $S_{\mathrm{j}}$, and duration, $\tau$. Such a simple load process has been shown to be an effective model for extreme service and environmental loads on NPP structures (Hwang, et al, 1987), since normal service loads challenge the structure to only a small fraction of its strength. With this assumption, the reliability function becomes,

$$
L(0, t)=\int_{0}^{\infty} \exp \left[-\lambda t\left(1-t^{-1} \int_{0}^{t} F_{s}(r g(x)) d x\right)\right] f_{R}(r) d r
$$

in which $f_{R}(r)=P D F$ of initial strength, $R(0)$, and $g(t)=R(t) / R(0)$ is a function that describes the degradation of strength in time. The limit state probability or probability of failure during $(0, t)$ is $F(t)$ $=1-L(0, t)$; note that $F(t)$ is not the same as $P_{f}(t)$ in Eqn 3 .

\subsection{Illustration of service life prediction}

Time-dependent reliability concepts are illustrated with a simple example of a concrete slab drawn from recent research on aging of reinforced concrete structures (Mori and Ellingwood, 1993). The slab was designed using the requirements for flexural strength in ACI standard 318 (Building 1989):

$$
0.9 R_{n}=1.4 D_{n}+1.7 L_{n}
$$

in which $R_{n}=$ nominal or code (characteristic) strength and $D_{n}, L_{n}=$ code-specified dead and live loads. The strength of the slab changes in time, initially increasing as the concrete matures and then decreasing due to reinforcement corrosion. This situation is illustrated conceptually by the sample functions, $r(t)$ and $s(t)$, of strength and load in Figure 1. Two other situations are illustrated for comparison, one in which strength degrades linearly to $90 \%$ of initial strength at 40 years and a second 


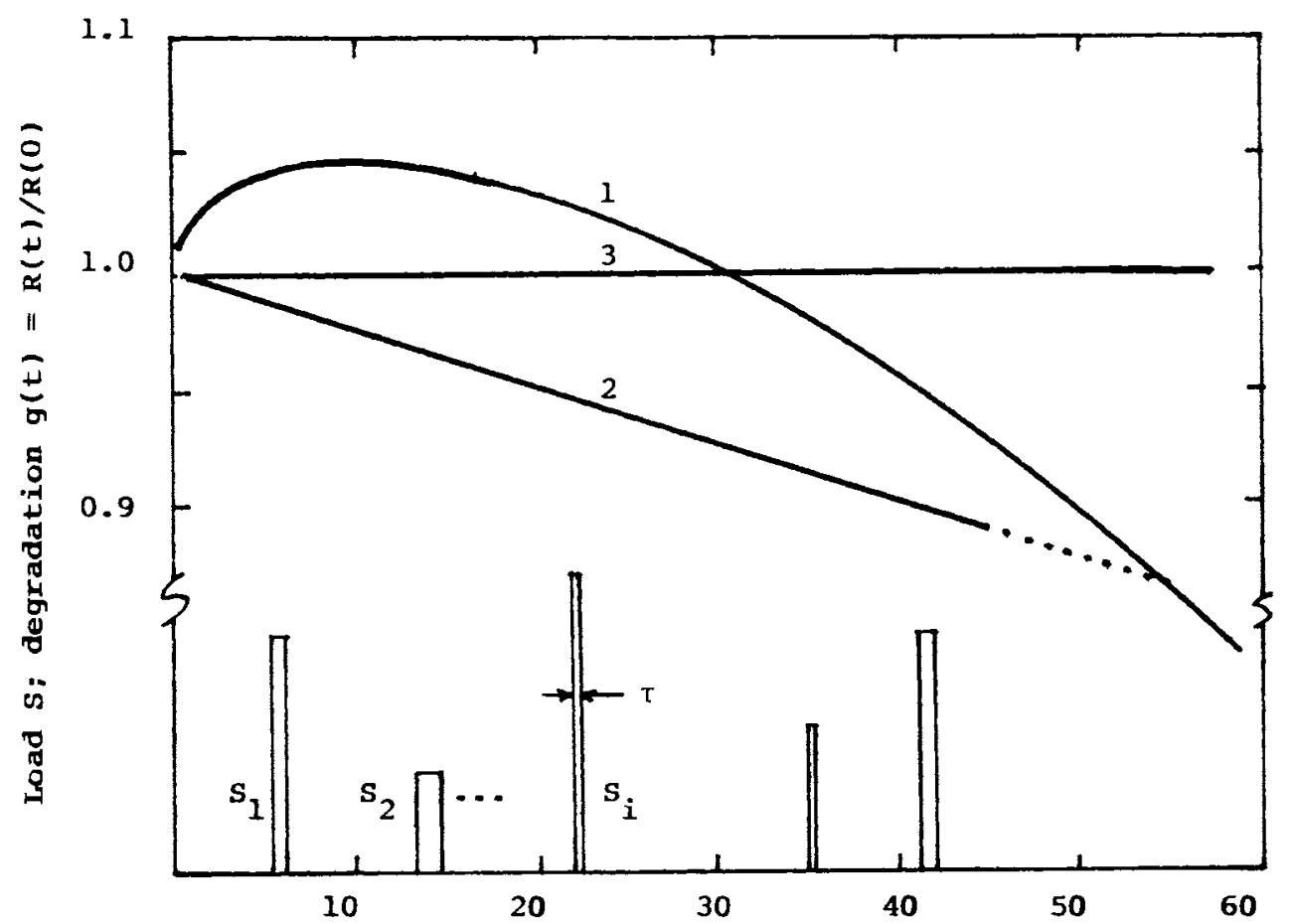

Figure 1. Sample functions of load and strength of concrete slab

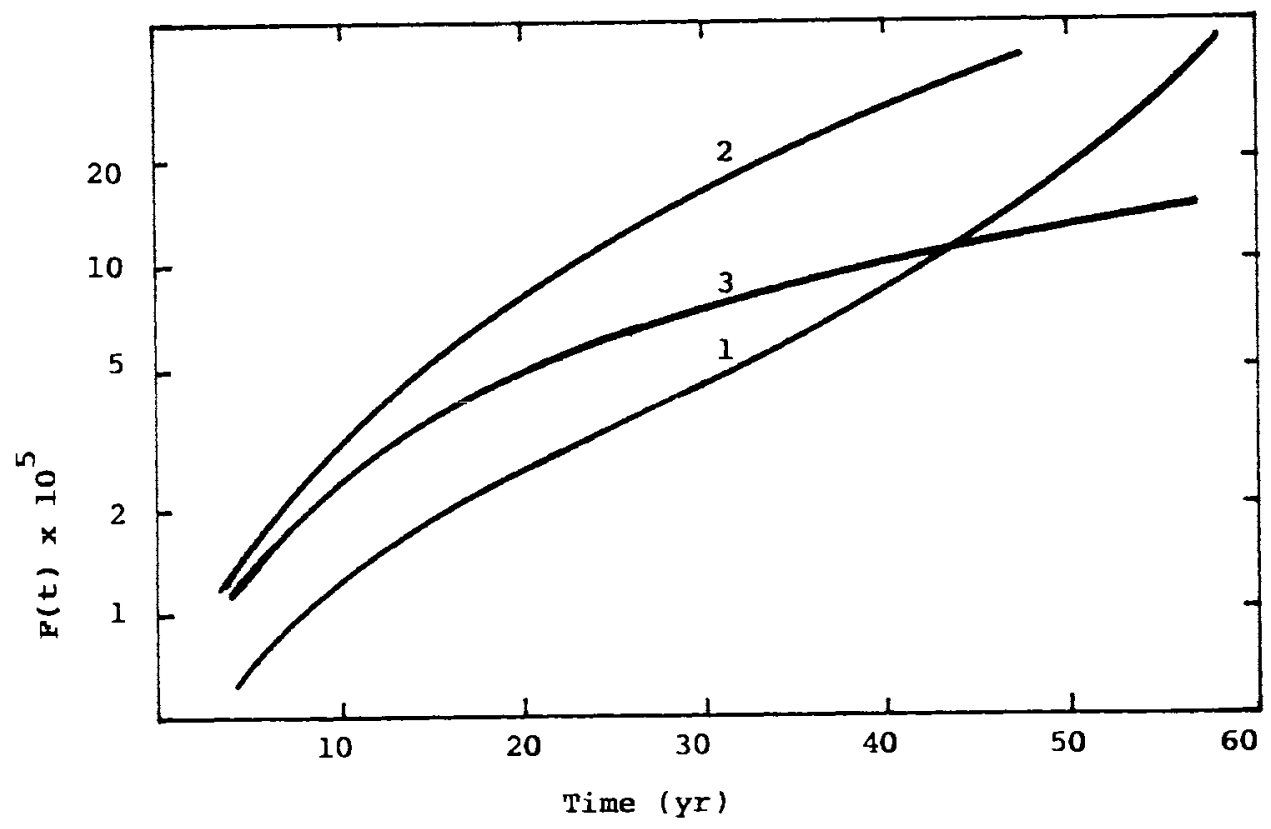

Figure 2. Failure probability of concrete slab 
in which the strength is constant in time. In general, the behavior of the resistance over time must be obtained from mathematical models describing the degradation mechanism(s) present (cf Eqn 1). The statistics used in the illustrations that follow are summarized in Table 1; their basis is provided elsewhere (Ellingwood and Mori, 1993).

Table 1. Statistics of strength and load

$\begin{array}{lccccc}\text { Parameter } & \text { Rate } & \text { Duration } & \text { Mean } & \text { COV } & \text { PDF } \\ \text { Flexure strength } & - & - & 1.12 \mathrm{M}_{\mathrm{n}} & 0.14 & \text { Lognormal } \\ \text { Dead load } & - & 60 \mathrm{yr} & 1.0 \mathrm{D}_{\mathrm{n}} & 0.07 & \text { Normal } \\ \text { Live load } & 0.5 / \mathrm{yr} & 0.25 \mathrm{yr} & 0.4 \mathrm{~L}_{\mathrm{n}} & 0.50 & \text { Type I }\end{array}$

Figure 2 compares the limit state probabilities $(F(t)=1-L(t)$ in Eqn 8) obtained for the three degradation models illustrated in Figure 1 for intervals $(0, t)$ ranging up to 60 years. When $R(t)=R(0)$ and no degradation in strength occurs, one obtains a result that is analogous to what has been done in probability-based code work to date. Neglecting strength degradation entirely in a time-dependent reliability assessment can be quite unconservative, depending on the time-dependent characteristics of strength.

\section{IN-SERVICE INSPECTION AND REPAIR}

\subsection{Condition assessment}

Forecasts of time-dependent reliability (e.g, Figure 2) enable the analyst to determine the time period beyond which the desired reliability of the structure cannot be ensured. At such a time, the structure should be inspected and its condition should be evaluated. Intervals of inspection and maintenance that may be required as a condition for continued operation can be determined from the time-dependent reliaability analysis. ISI/M is a routine part of managing aging and deterioration in many engineered facilities (ASME, 1992); work already is underway to develop reliability-based policies for offshore platforms (Madsen, et al, 1989) and aircraft (Yang, 1994). Reportedly, however, utilities generally do not perform regular inspections of NPP structures other than casual visual observations or the monitoring of ungrouted prestressing tendons required in RG 1.35 (Regulatory, 1990). Many aging mechanisms may not be easily detectable visually, and can lead to cracking and strength degradation.

Inspecting a structure reveals something about its in-service condition that enables the PDF of strength to be updated. The information gained from inspection usually involves several structural variables, including dimensions, defects, and perhaps an indirect measure of strength or stiffness such as ultrasonic pulse velocity (Snyder, et al, 1992). If the results of the inspection can be collected in event $\mathrm{B}$, the updated PDF of resistance can be obtained from Bayes theorem:

$$
\mathrm{f}_{\mathrm{R}}(\mathrm{r} \mid \mathrm{B})=\mathrm{CK}(\mathrm{B} \mid \mathrm{r}) \mathrm{f}_{\mathrm{R}}(\mathrm{r})
$$

in which $f_{R}(r)$ is the PDF prior to inspection, $K(B \mid r)$ is denoted the likelihood function, and $C$ is a normalizing constant to make $f_{R}(r \mid B)$ a legitimate PDF. If the structure subsequently is repaired, the 
PDF of strength is again updated using Eqn 10, in which the conditioning event B now depends on the effectiveness of the repair operation. Various repair strategies have been identified as part of the SAG program (Krauss, 1994).

Although in theory one can associate a likelihood function $\mathrm{K}(\mathrm{B} / \mathrm{r})$ with each inspection technology and repair method, in practice this has been found to be very difficult to do for reinforced concrete structures. The effects of nondestructive evaluation and repair on structural capacity are difficult to determine because of the heterogenous nature of reinforced concrete as a construction material, inaccessibility of certain critical components, and difficult measurement conditions in-situ. Uncertainties in the ISI/M process stem from the imperfect nature of the flaw detection process (represented by curves showing the probability of detecting strength-reducing defects of a given size for the NDE technology selected), from unpredictable gain in strength following repair (depending on repair methods selected), and other factors. These uncertainties must be reflected properly in the conditional PDF, $\mathrm{f}_{\mathrm{R}}(\mathrm{r} \mid \mathrm{B})$, if the updated reliability analysis is to be useful in decision-making.

The time-dependent reliability analysis is re-initialized following ISI/M using the updated $f_{R}(r)$ in Eqn 10 in place of $f_{R}(r)$. This updating causes the instantaneous failure rate or hazard function, $h(t)$, to be discontinuous. Beneficial maintenance causes the hazard function to decrease and leads to improvement in the overall reliability estimated with respect to some future service or inspection interval.

\subsection{Illustration of reliability updating}

As an illustration of the updating process, we consider the same reinforced concrete slab as before. The mechanism causing degradation is assumed to be corrosion of the reinforcement. The mean induction period is assumed to be 10 years. The corrosion rate (from Eqn 1) is assumed to be a lognormal random variable, with mean of $30 \mu \mathrm{m} / \mathrm{yr}$ and coefficient of variation 0.5 . We consider a 60 -year service life and envision three alternative strategies: (1) The slab is fully inspected at 30 years with a NDE technique capable of detecting defects causing a $1 \%$ (or more) reduction in strength (denoted $x_{\mathrm{th}}=0.01$ ), and is fully repaired; (2) The slab is inspected at 20,30, 40 and 50 years with a NDE technique capable of detecting only defects causing an $8 \%$ (or more) reduction in strength (denoted $x_{\text {th }}=0.08$ ); or (3) The slab is not inspected or repaired. Policy (1) involves a single thorough inspection at midlife, while policy (2) involves several more superficial inspections but at more frequent intervals. The mean degradation functions and time-dependent failure probabilities, $F(t)$ $1-L(0, t)$ are illustrated in Figures 3 and 4. Note that a performance goal that $F(60)$ be less than 1.5 $\mathrm{x} 10^{-4}$ may be achieved by several ISI/M policies. The selection of the appropriate policy depends on the total cost associated with each.

\subsection{Optimum inspection/repair strategies}

Costs of inspection and maintenance can be a significant part of the overall life-cycle cost of a reinforced concrete structure. Tradeoffs between the extent of inspection, cost, and required level of reliability can be performed systematically by reliability-based optimization methods using an objective function that takes into account costs of inspection, repair and failure. One might consider the following optimization problem:

(11a) Minimize: $\mathrm{C}_{\mathrm{t}}=\mathrm{C}_{\text {ins }}+\mathrm{C}_{\text {rep }}+\mathrm{C}_{\mathrm{f}} \mathrm{F}(\mathrm{t})$

(11b) Subject to: $F(t) \leq P_{\text {target }}$

in which $\mathrm{C}_{\mathrm{ins}}=$ inspection cost, $\mathrm{C}_{\mathrm{rep}}=$ repair cost, $\mathrm{C}_{\mathrm{f}}=$ loss due to failure, and $\mathrm{P}_{\text {target }}=$ established target 


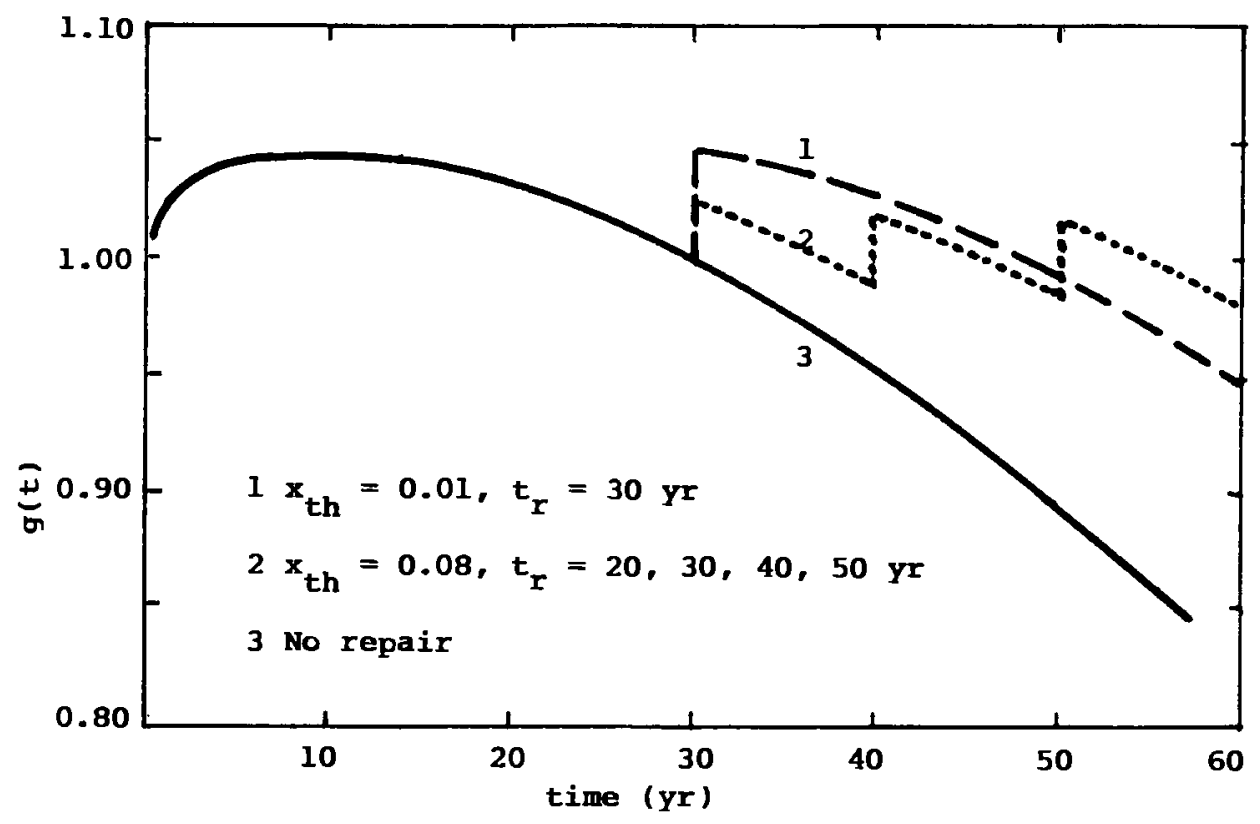

Figure 3. Mean degradation functions for slab under alternate ISI/M policies

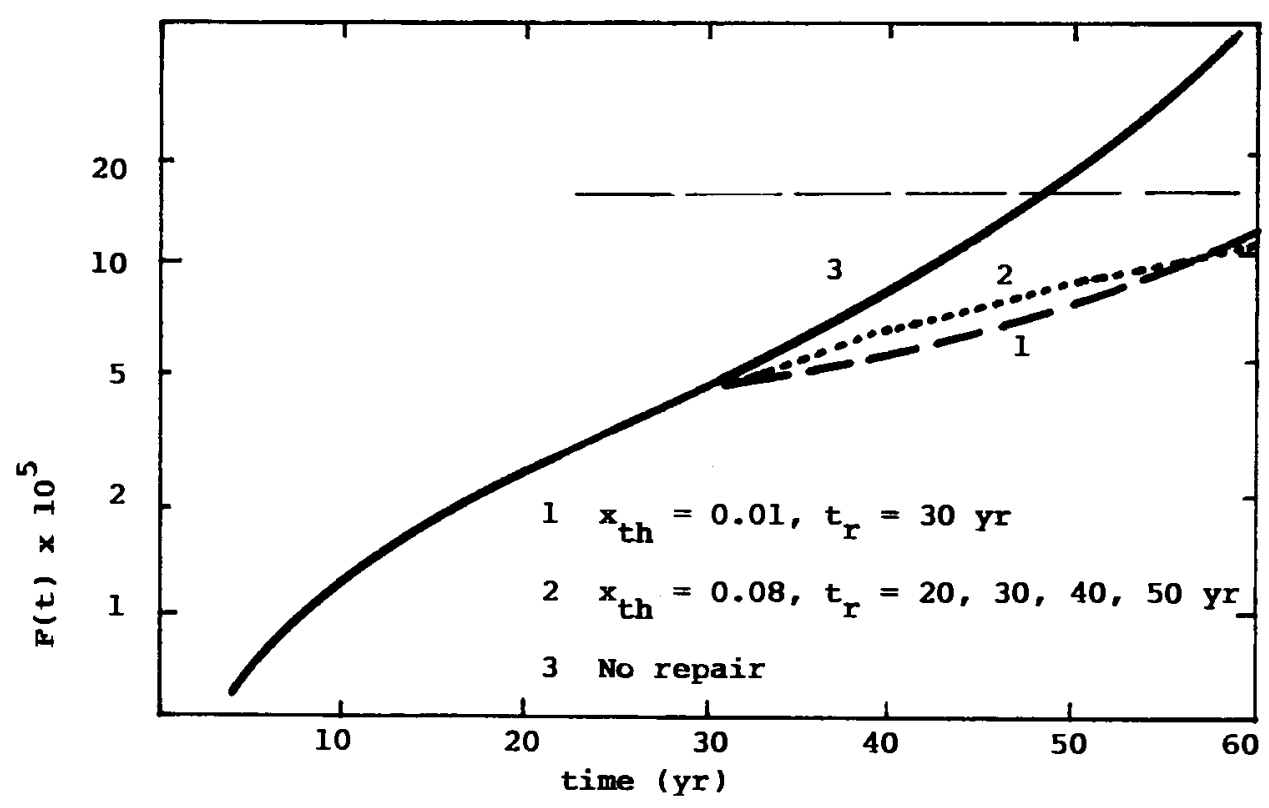

Figure 4. Failure probability of slab for alternate ISI/M policies 
failure probability during service life $t$. Cost $\mathrm{C}_{\text {ins }}$ depends on the quality and extent of inspection, while $\mathrm{C}_{\text {rep }}$ is a linear function of the area to be repaired and a nonlinear function of the damage to be repaired (Mori and Ellingwood, 1994a, 1994b). The variables in the optimization are the inspection times, the extent of inspection and the threshold of detection of the NDE device, $x_{t h}$, and the effectiveness or quality of repair.

The socioeconomic impact of failure (unserviceability) of concrete components in NPPs cannot be assessed in absolute terms at present. However, sensitivity studies can be conducted by varying the relative costs in Eqn 11a in fixed ratios $C_{\mathrm{ins}}: \mathrm{C}_{\mathrm{rep}}: \mathrm{C}_{\mathrm{f}}$ (Ellingwood and Mori, 1994b). Such studies show that when failure costs dominate over other costs and the aging mechanism causes essentially linear degradation in strength over time, the optimal policy is to perform in-service inspection/maintenance at essentially uniform intervals.

\section{CONCLUSIONS}

When there are limited resources for ISI/M available, it often is most effective to select a few safety-critical components and focus the monitoring efforts on these components (Hookham, 1991; Ellingwood and Mori, 1993). The reliability analysis can be used to identify those components that are most significant from a risk viewpoint, thus avoiding the need for costly monitoring. It appears that if the cost of failure is orders of magnitude larger than inspection and maintenance costs, the optimal ISI/M policy is to inspect at nearly uniform intervals over the projected service life or service life extension.

\section{ACKNOWLEDGEMENT}

This research was supported through Grant No. 19X-SD684V from Oak Ridge National Laboratory, with Dr. D. J. Naus program manager. This support is gratefully acknowledged.

\section{REFERENCES}

ASME (1992). "Reliability-based inspection - development of guidelines." Report NUREG/GR-0005 (prepared by the American Society of Mechanical Engineers), U.S. Nuclear Regulatory Commission, Washington, DC.

"Building code requirements for reinforced concrete (ACI Standard 318-89)." American Concrete Institute, Detroit, MI.

Clifton, J.R. and Knab, L.I. (1989). "Service life of concrete." NUREG/CR-5466 (prepared by the National Bureau of Standards), U.S. Nuclear Regulatory Commission, Washington, DC.

Ellingwood, B. (1992). "Probabilistic risk asessment." in Engineering Safety (D. Blockley, ed.), McGraw-Hill Book Company, Ltd., London, pp. 89-116.

Ellingwood, B. and Mori, Y. (1993). "Probabilistic methods for condition assessment and life prediction of concrete structures in nuclear plants." Nuc. Engrg. and Des. 142:155-166.

Hookham, C.J. 91991). "Structural aging assessment methodology for concrete structures in nuclear power plants." ORNL/NRC/LTR-90/17 (prepared by Multiple Dynamics Corp.), Oak Ridge National Laboratory, Oak Ridge, TN. 
Hwang, H., Ellingwood, B., Shinozuka, M. and Reich, M. (1987). "Probability based design criteria for nuclear plant structures." J. Str. Engrg. ASCE 11395):925-942.

Krauss, P.D. (1994). "Repair materials and techniques for concrete structures in nuclear power plants." ORNL/NRC/LTR-93/28 (prepared by Wiss, Janney, Elstner and Assoc.), Oak Ridge National Laboratory, Oak Ridge, TN.

Madsen, H. Sorensen, J.D. and Olesen, R. (1989). "Optimal inspection planning for fatigue damage of offshore structures." in Structural Safety and Reliability (Proc. ICOSSAR '89, Vol. III, p. 20992106), American Society of Civil Engineers, New York, NY.

Mori, Y. and Ellingwood, B. (1993). "Methodology for reliability-based condition assessment application to concrete structures in nuclear plants." Report NUREG/CR-6052, U.S. Nuclear Regulatory Commission, Washington, DC.

Mori, Y. and Ellingwood, B. (1994a). "Maintaining reliability of concrete structures I: role of inspection/repair." J. Struct. Engrg. ASCE 120(3):824-845.

Mori, Y. and Ellingwood, B. (1994b). "Maintaining reliability of concrete structures II: optimum inspection/repair." J. Struct. Engrg. ASCE 120(3):846-862.

Naus, D.J., et al (1993). "An overview of the ORNL/NRC program to address aging of concrete structures in nuclear power plants." Nuc. Engrg. and Des. 142:327-339.

Regulatory Guide 1.35 (1990). "Inservice inspection of ungrouted tendons in prestressed concrete containments." U.S. Nuclear Regulatory Commission, Washington, DC.

Shah, V.N. and Hookham, C.J. (1994). "Aging management of light water reactor concrete containments." Proc. 21st Water Reactor Safety Information Meeting, NUREG/CP-0133, Vol. 3, pp. 283-306, U.S. Nuclear Regulatory Commission, Washington, DC.

Snyder, K.A., Clifton, J.R. and Carino, N.J. (1992). "Nondestructive evaluation of the in-place compressive strength of concrete based upon limited destructive testing." NISTIR 4874, National Institute of Standards and Technology, Gaithersburg, MD.

Veneziano, D., Grigoriu, M. and Comell, C.A. (1977). "Vector process models for system reliability." J. Engrg. Mech. ASCE 103(3):441-460.

Vora, J.P. et al (1991). "Nuclear plant aging research (NPAR) program plan." Report NUREG-1144, U.S. Nuclear Regulatory Commission, Washington, DC.

Yang, J. (1994). "Application of reliability methods to fatigue, quality assurance and maintenance." in Structural Safety and Reliability (Proc. ICOSSAR '93, Vol. I, pp. 3 - 18), A.A. Balkema, Rotterdam, The Netherlands. 